\title{
IMPLANTAÇÃO DE CANTEIRO DE PLANTAS MEDICINAIS COMO SUBSÍDIO PARA O ENSINO DE BOTÂNICA NO 3․ ANO DO ENSINO MÉDIO DA ESCOLA ESTADUAL PIRASSUNUNGA, PIRASSUNUNGA, SP.
}

\author{
PEDROSO-DE-MORAES, Cristiano ${ }^{1}$ \\ BETTINI, Daniel Ricardo Biazoli ${ }^{2}$ \\ BERNARDO, Zilda Maria ${ }^{3}$
}

\begin{abstract}
RESUMO: O presente trabalho teve por objetivo propiciar o ensino de Botânica por meio de interdisciplinaridade com a disciplina de Química e transdisciplinarmente com o ensino de Etnobotânica, discutindo recomendações da Organização Mundial da Saúde (OMS) em relação à utilização de plantas medicinais para a manutenção da saúde das populações de países pobres e/ou em desenvolvimento. Este trabalho foi fundamentado em uma pesquisa qualiquantitativa participativa como procedimento metodológico, enquadrando-se aos propósitos iniciais da pesquisa para a consecução de seus objetivos. Desta forma, foi utilizada a modalidade pesquisa-ação, por ser capaz de proporcionar a manifestação do coletivo. A intervenção realizada com os alunos do $3^{\circ}$. Ano A do Ensino Médio da Escola Estadual Pirassununga, permitiu a integralização dos conteúdos de Botânica (Sistemática, Morfoanatomia, Fisiologia, Evolução e Produção Vegetal), com os de Química (Reconhecimento de moléculas e funções orgânicas), por meio de aulas teóricas e práticas sobre obtenção, cultivo, plantio, princípios ativos e utilização de plantas medicinais (fitoterápicos). interdisciplinaridade, a transdisciplinaridade, e o desenvolvimento de aulas práticoteóricas diversificadas, foram às formas com as quais se atingiu a eficácia em relação ao ensino-aprendizagem, atestadas pelos resultados obtidos nas avaliações estatísticas e nos depoimentos dos discentes com relação à importância dos conhecimentos Etnobotânicos e das recomendações da OMS sobre a utilização de plantas medicinais por pessoas de baixa renda. Relaciona-se também o sucesso da intervenção com o planejamento sistemático do projeto que possibilitou a integração da equipe gestora, docentes e alunos na realização das etapas bimestrais que culminaram na autorregulação da aprendizagem do alunado.
\end{abstract}

Palavras-chave: Interdisciplinaridade. Fitoterápicos. Projetos didáticos. Transdisciplinaridade.

SUMMARY: (Implantation of flowerbed of medicinal plants as a subsidy for Botanical teaching in the 3 rd. grade A of High School in Escola Estadual Pirassununga, Pirassununga, SP.) The present research had the objective of promoting the teaching of Botany through interdisciplinarity with the discipline of Chemistry and transdisciplinarily with the teaching of Ethnobotany, discussing recommendations of the World Health Organization (WHO) regarding the use of medicinal plants for the maintenance of health of poor and/or developing countries. This work was based on a participatory qualitative-quantitative research as a methodological procedure, according to the initial research purposes to achieve its objectives. In this way, the research-action modality was used, because it was able to provide the manifestation of the collective. The intervention performed with the students of the 3rd. grade A of High School in Escola Estadual Pirassununga, allowed the integration of the contents of Botany (Systematics, Morphoanatomy, Physiology, Evolution and Plant Production), with Chemistry (Recognition of molecules and organic functions), through theoretical and practical classes on obtaining, cultivating, planting, active principles and the use of medicinal plants (herbal medicines). Interdisciplinarity, transdisciplinarity, and the development of diverse practical-theoretical classes, were the ways in which efficacy was achieved in relation to teaching and learning, attested by the results obtained in the statistical evaluations and in the testimonies of the students regarding the importance of the knowledge Ethnobotanical and WHO recommendations on the use of medicinal plants by low-income people. It is also related to the success of the intervention with the systematic planning of the project that allowed the integration of the management team, teachers and students in the accomplishment of the bimonthly stages that culminated in the self-regulation of the student's learning.

Keywords: Interdisciplinarity. Phytotherapics. Didactic projects. Transdisciplinarity.

\footnotetext{
${ }^{1}$ Prof. de Botânica e Ecologia Uniararas

${ }^{2}$ PEB II de Química Escola Estadual Pirassununga

${ }^{3}$ Coordenadora do Ensino Fundamental e Médio da Escola Estadual Pirassununga
} 


\section{INTRODUÇÃO}

O ensino de Biologia, prioritariamente objetiva: a aprendizagem de conceitos básicos, a habilidade de análise do processo de pesquisa científica e a compreensão das implicações sociais da ciência e da tecnologia (KRASILCHIK, 2004). Contudo, na maior parte das escolas brasileiras o ensino de Biologia, mais particularmente de Botânica ocorre, principalmente, por meio de aulas expositivas tradicionais, sendo que tal conduta pedagógica torna, na maioria das vezes, as aulas desestimulantes e desinteressantes, culminando no desenvolvimento, por parte do aluno, do hábito de "decorar a matéria para fazer a prova". Isto resulta na absorção passiva dos conteúdos ministrados (COSTA; MARINHO, 2012), ou em uma não aprendizagem real dos conteúdos, dificultando a ação discente de partícipe direto da construção de seu próprio conhecimento.

Mesmo com todos os esforços realizados para alteração dessa práxis, ainda estamos distantes de conseguir os resultados esperados quanto à diversificação pedagógica no ensino da disciplina (PEDROSODE-MORAES et al., 2015). O modelo pautado em conteúdo puramente exposto em aulas palestradas se perpetua, e não propicia uma aprendizagem eficiente e eficaz dos conteúdos biológicos escolares. Sob tal aspecto, salienta-se que para o ensino de Biologia:

(...) a educação deste componente curricular deve proporcionar a todos os estudantes a oportunidade de desenvolver capacidades que neles despertem a inquietação diante do desconhecido, buscando explicações lógicas e razoáveis, levando os educandos a realizar julgamentos e tomar decisões fundamentadas em critérios objetivos (BIZZO, 1998, p.54).

Dessa forma, investigações educacionais necessitam aterem-se também ao desenvolvimento de aulas de Biologia que visem práticas metodológicas capazes de auxiliar na aprendizagem dos conhecimentos científicos, relacionando-os à classificação e evolução biológica e às práticas de preservação ambiental e da biodiversidade (SENICIATO; CAVASSAN, 2004). Tal afirmação corrobora o fato de serem escassas as investigações que analisam o desenvolvimento de conhecimentos nestas áreas em aulas teórico-práticas (PEDROSO-DE-MORAES et al., 2015). Sob este aspecto, ressalta-se que os princípios relegados à interdisciplinaridade e, principalmente, neste caso, a transdisciplinaridade rompem barreiras entre disciplinas e dentro do próprio componente curricular, permitindo uma integração do currículo de forma espiral, como preconiza a Proposta Curricular do Estado de São Paulo (MENDONÇA et al., 2008). Esta estruturação tem com objetivo permitir a construção de conhecimento global, capaz de superar a concepção fragmentada (SANTOS, 2002; PEDROSO-DE-MORAES et al., 2015).

Assim, a integralização de conhecimentos não advindos somente das Ciências da Natureza, mas também das Ciências Humanas é importante para o desenvolvimento dos discentes em plenos cidadãos capazes de atuar e opinar em sociedade. Como exemplo dessa integralização, podemos apontar a realização de algumas investigações que relatam que a utilização de plantas medicinais, caracteriza excelente "veículo" para a compreensão dos conteúdos de vários componentes curriculares, principalmente os relacionados ao ensino de Botânica (COSTA; MARINHO, 2012).

A utilização de plantas medicinais permite a abordagem de conteúdos interdisciplinares como: etnobotânica [fronteira entre a botânica e a antropologia cultural (ALBUQUERQUE, 2005)] e bioquímica. Também arremete ao ensino de conteúdos transdisciplinares como: classificação biológica, evolução, morfoanatomia, fisiologia e produção vegetal (PEREIRA; SIQUEIRA, 2013). Além da aplicação de uma metodologia ativa e capaz de cativar os alunos para a aprendizagem dos conteúdos 
supracitados, o desenvolvimento do presente trabalho relacionado à plantas medicinais, justifica-se também, por agregar:

(...) estudos de caráter filosófico, metodológico e trabalhos que pretendem constituir na solução (ou na busca dela) de problemas práticos relacionados às preocupações quanto ao desenvolvimento humano, conservação da natureza, uso de recursos e ecossistemas, bem como questões de segurança alimentar e saúde pública (PEREIRA; SIQUEIRA, 2013, p.1-2).

O presente trabalho teve por objetivo geral propiciar o ensino de Botânica por meio da transdisciplinaridade envolvendo os conteúdos: classificação biológica, evolução bioquímica, morfoanatomia, fisiologia e produção vegetal presentes na Proposta Curricular do Estado de São Paulo e, como objetivos específicos discutir temas interdisciplinares como o uso de fitoterápicos por populações indígenas e urbanas e as recomendações da Organização Mundial da Saúde (OMS-ONU) em relação à utilização de plantas medicinais quanto à saúde das populações de países pobres e/ou em desenvolvimento.

\section{MATERIAL E MÉTODOS}

Este trabalho foi baseado em pesquisa quali-quantitativa participativa como método de intervenção pedagógica, relacionando-o aos propósitos iniciais desta investigação, visando a consecução dos objetivos propostos (PEDROSO-DE-MORAES et al., 2015; 2016). Assim, optou-se pela utilização de uma pesquisa-ação, por proporcionar manifestações coletivas (SILVA et al., 2014).

O trabalho foi desenvolvido junto aos alunos da $3^{\text {a }}$. Série A do Ensino Médio da Escola Estadual Pirassununga, vinculada à Diretoria de Ensino de Pirassununga, SP, do $1^{\circ}$. ao $4^{\circ}$. bimestres de 2016. O desenvolvimento do projeto ocorreu com a participação de 32 alunos e praticamente, durou todo o ano escolar. Foi solicitado, na primeira semana do ano letivo (sexta-feira - aula dupla), que os alunos se dividissem em quatro grupos (equipes), contendo oito integrantes cada. Após a formação das equipes, foi passada na lousa, pelo professor da disciplina de Biologia, uma relação de plantas medicinais, num total de 16 espécies, que fizeram parte do rol das ervas e arbóreas fitoterápicas utilizadas no projeto (Tabela 1).

Tabela 1 - Plantas medicinais utilizadas para o ensino de Botânica para os alunos do $3^{\circ}$. Ano do Ensino Médio da Escola Estadual Pirassununga, Pirassununga, SP.

(Continua)

\begin{tabular}{|c|c|c|c|c|}
\hline Nome Popular & Nome Científico & Grupo Vegetal & $\begin{array}{l}\text { Famílias } \\
\text { Botânicas }\end{array}$ & Princípio Ativo \\
\hline Arnica de jardim & Solidago microglossa & $\begin{array}{l}\text { Angiosperma } \\
\text { dicotiledônea }\end{array}$ & Asteraceae & $\begin{array}{c}\text { Flavonoides, } \\
\text { taninos e } \\
\text { saponinas }\end{array}$ \\
\hline Arruda & Ruta graveolens & $\begin{array}{l}\text { Angiosperma } \\
\text { dicotiledônea }\end{array}$ & Rutaceae & $\begin{array}{l}\text { Alcaloides e } \\
\text { flavonoides }\end{array}$ \\
\hline Babosa & Aloe vera & $\begin{array}{l}\text { Angiosperma } \\
\text { dicotiledônea }\end{array}$ & Liliaceae & $\begin{array}{l}\text { Polissacárido e } \\
\text { prostaglandinas }\end{array}$ \\
\hline Bálsamo & Sedum dendroideum & $\begin{array}{l}\text { Angiosperma } \\
\text { dicotiledônea }\end{array}$ & Crassulaceae & $\begin{array}{l}\text { Mucilagens, } \\
\text { terpenoides e } \\
\text { taninos }\end{array}$ \\
\hline
\end{tabular}


Tabela 1 - Plantas medicinais utilizadas para o ensino de Botânica para os alunos do $3^{\circ}$. Ano do Ensino Médio da Escola Estadual Pirassununga, Pirassununga, SP.

(Conclusão)

\begin{tabular}{|c|c|c|c|c|}
\hline Nome Popular & Nome Científico & Grupo Vegetal & $\begin{array}{l}\text { Famílias } \\
\text { Botânicas }\end{array}$ & Princípio Ativo \\
\hline Boldo da terra & Plectranthus barbatus & $\begin{array}{l}\text { Angiosperma } \\
\text { dicotiledônea }\end{array}$ & Lamiaceae & $\begin{array}{l}\text { Óleo essencial, } \\
\text { cânfora e } \\
\text { verbenona }\end{array}$ \\
\hline Cavalinha & Equisetum arvense & $\begin{array}{l}\text { Pteridófita } \\
\text { Equisetinea }\end{array}$ & Equisetaceae & $\begin{array}{l}\text { Flavonoides, } \\
\text { taninos e } \\
\text { saponinas }\end{array}$ \\
\hline $\begin{array}{l}\text { Erva de Santa- } \\
\text { Maria }\end{array}$ & $\begin{array}{l}\text { Chenopodium } \\
\text { ambrosioides }\end{array}$ & $\begin{array}{l}\text { Angiosperma } \\
\text { dicotiledônea }\end{array}$ & Chenopodiaceae & $\begin{array}{c}\text { Esteroides, } \\
\text { saponinas, } \\
\text { terpenos, } \\
\text { ascaridiol }\end{array}$ \\
\hline Erva-cidreira & Cymbopogon citratus & $\begin{array}{l}\text { Angiosperma } \\
\text { Monocotiledônea }\end{array}$ & Poaceae & $\begin{array}{l}\text { Citral, geraniol, } \\
\text { mirceno, } \\
\text { citronelal }\end{array}$ \\
\hline Guaco & Mikania glomerata & $\begin{array}{l}\text { Angiosperma } \\
\text { dicotiledônea }\end{array}$ & Asteraceae & $\begin{array}{l}\text { Flavonoides, } \\
\text { cumarinas, } \\
\text { terpenos }\end{array}$ \\
\hline Hortelã-pimenta & Mentha X piperita & $\begin{array}{l}\text { Angiosperma } \\
\text { dicotiledônea }\end{array}$ & Lamiaceae & $\begin{array}{l}\text { Flavonoides e } \\
\text { polifenois }\end{array}$ \\
\hline Insulina & Cissus sicyoides & $\begin{array}{l}\text { Angiosperma } \\
\text { dicotiledônea }\end{array}$ & Vitaceae & $\begin{array}{c}\text { Esteróis, } \\
\text { quinonas, } \\
\text { alcaloides e } \\
\text { saponinas }\end{array}$ \\
\hline Manjericão & Ocimum basilicum & $\begin{array}{l}\text { Angiosperma } \\
\text { dicotiledônea }\end{array}$ & Lamiaceae & $\begin{array}{l}\text { Óleos essenciais, } \\
\text { taninos, saponinas e } \\
\text { flavonoides }\end{array}$ \\
\hline Maracujá-azedo & Passiflora edulis & $\begin{array}{l}\text { Angiosperma } \\
\text { dicotiledônea }\end{array}$ & Passifloraceae & $\begin{array}{l}\text { Flavonoides e } \\
\text { alcaloides }\end{array}$ \\
\hline Melissa & Melissa officinalis & $\begin{array}{l}\text { Angiosperma } \\
\text { dicotiledônea }\end{array}$ & Lamiaceae & $\begin{array}{l}\text { Terpenos e } \\
\text { taninos }\end{array}$ \\
\hline Romã & Punica granatum & $\begin{array}{l}\text { Angiosperma } \\
\text { dicotiledônea }\end{array}$ & Lytraceae & $\begin{array}{l}\text { Alcaloides e } \\
\text { taninos }\end{array}$ \\
\hline Urucum & Bixa orellana & $\begin{array}{l}\text { Angiosperma } \\
\text { dicotiledônea }\end{array}$ & Bixaceae & $\begin{array}{c}\text { Terpenos e } \\
\text { taninos }\end{array}$ \\
\hline
\end{tabular}

Logo após, teve início o desenvolvimento das ações teórico-práticas visando à aprendizagem dos conteúdos selecionados. As intervenções pedagógicas foram divididas em quatro etapas ao longo do ano letivo (uma por bimestre), sendo utilizadas duas aulas da disciplina de Biologia do $1^{\circ}$. ao $3^{\circ}$. bimestres e seis no $4^{\circ}$. bimestre. A disciplina de Química, também utilizou duas aulas no $4^{\circ}$. Bimestre.

As divisões temporais de trabalho foram elaboradas com a finalidade de não comprometer o ensino dos demais conteúdos das disciplinas preconizados pela Proposta Curricular do Estado de São Paulo (MENDONÇA et al., 2008).

$1^{a}$. etapa: No $1^{\circ}$. bimestre, logo após a listagem passada pelo professor, os alunos escolheram democraticamente, quatro espécies de plantas para cada grupo. As plantas, em número de quatro espécimes de cada espécie, foram obtidas pelos próprios alunos ainda no bimestre e cultivadas em suas 
residências, na tentativa de garantir a sobrevivências das mudas até o seu plantio definitivo, o qual foi realizado no $4^{\mathrm{a}}$. bimestre.

A solicitação do professor, nas primeiras duas aulas do $1^{\circ}$. bimestre com a turma, também visou gerar dúvidas nas mentes do alunado, como: 1 - como obter a muda de destas planta? 2 - Como cuidar da planta para que viva até o final do ano? 3 - Alguém na minha casa sabe alguma coisa dessa planta? Ao professor, ainda, nesta aula, coube explicar técnicas fitotécnicas ${ }^{4}$ básicas de propagação e plantio em vasos.

$2^{a}$. etapa: Nas duas primeiras aulas do $2^{\circ}$. bimestre, sem aviso prévio, o professor solicitou aos alunos um pequeno relatório sobre a obtenção das mudas, cultivo e possíveis informações sobre as espécies cultivadas. Logo após, o professor pediu que os alunos preenchessem os dados relativos aos nomes científicos, grupo vegetal [Briófitos, Pteridófitos, Gimnospermas, Angiospermas - monocotiledôneas ou dicotiledôneas], famílias botânicas e princípios ativos de casa espécie (Tabela 1).

$3^{a}$. etapa: Nas duas primeiras aulas do $3^{\circ}$. bimestre, o professor pediu que os alunos confeccionassem uma cartilha de plantas medicinais do colégio. A cartilha e excertos (Figura 1) dela também foram utilizados para um evento da UE chamado de "Mostra Pedagógica" (uma espécie de feira de ciências e artes/cultura), realizado no $4^{\circ}$. bimestre de 2016. Nesta mostra, os alunos expuseram conceitos de Etnobotânica, com ênfase em fitoterapia, ao lado do canteiro implantado no colégio.

4. etapa: Nas duas últimas aulas do mês de outubro, os alunos fizeram o plantio das plantas medicinais em canteiro existente nas proximidades do pátio e da cantina da UE. Na primeira semana do mês de novembro, os professores de Biologia e Química, fizeram uma explanação, utilizando duas horas aula, cada um, sobre: as características botânicas (morfoanatomia e fisiologia) e os princípios ativos das plantas (moléculas e funções químicas orgânicas).

No intuito de avaliar a aprendizagem após a execução do trabalho, foi elaborado um questionário com questões objetivas e dissertativas, respondido pelos alunos uma semana após o final da intervenção e, corrigido pelos professores componentes do projeto (SENICIATO; CAVASSAN, 2004; PEDROSO-DEMORAES et al., 2015; 2016).

O questionário foi subdividido em duas partes: Parte I - conteúdo apresentado pelos professores de Biologia e Química, para a verificação da aprendizagem de conteúdo especifico (uso de seis questões objetivas e uma dissertativa) (Quadro 1). Parte II - aplicação e estrutura do projeto, para a avaliação por parte dos discentes (questões objetivas e produção de mini texto contextualizando a importância do projeto) da eficácia da intervenção (Quadro 2). Todos os resultados obtidos foram expressos em porcentagem e disponibilizados em gráficos (adaptado de PEDROSO-DE-MORAES et al., 2016).

\footnotetext{
${ }^{4}$ (fitotecnia - área da agronomia voltada à produção vegetal).
} 
Figura 1 - Modelo de descrição de planta medicinal utilizado para a produção da cartilha de plantas medicinais da Escola Estadual Pirassununga, Pirassununga, SP.

\section{Insulina (Cissus sicyoides) - Vitaceae}

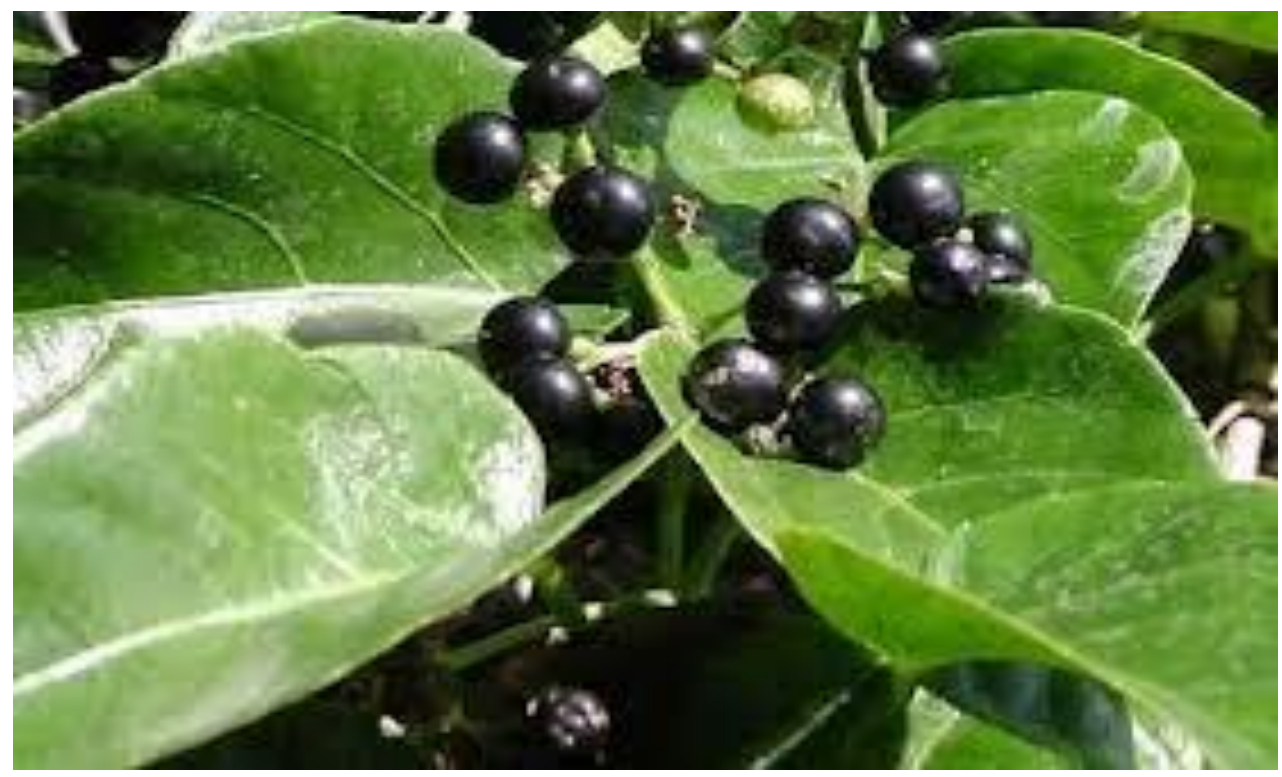

Fonte: TOP TROPICAL (2016).

\section{Descrição botânica:}

Princípios ativos:

Uso fitoterápico (como usar): 
Quadro 1 - Questionário pedagógico submetido aos alunos do terceiro ano do ensino médio da Escola Estadual Pirassununga, uma semana após a implantação do canteiro medicinal e da realização das aulas teórico-práticas pelos professores das disciplinas de Biologia e Química.

\section{CONTEÚDO BIOLÓGICO-QUÍMICO}

1 - As plantas medicinais, segundo a OMS (ONU), são importantes, pois:

a) Constituem importante fonte de tratamento fitoterápico para populações de baixa renda.

b) Constituem fonte de tratamento mais eficaz que os fármacos alopáticos.

c) São fontes de tratamento fitoterápico para populações que apresentam acesso a alopáticos.

d) Representam importância relacionada à biodiversidade, mas não se relacionam as condições socioeconômicas populacionais.

2 - As substâncias benéficas à saúde das pessoas presentes nas plantas medicinais são chamadas de:

a) Venenos.

b) Princípios ativos.

c) Compostos aromáticos.

d) Compostos voláteis.

3 - O ramo do conhecimento humano que estuda o uso de plantas medicinais por comunidades selvagens e urbanas é chamado de:

a) Etnofarmacobotânica.

b) Botânica.

c) Farmácia e Bioquímica.

d) Bioquímica.

4 - O conhecimento primordial sobre plantas medicinais no Brasil se deve em maior parte às etnias:

a) Branco-europeias e asiáticas.

b) Africanas e asiáticas.

c) Africanas e indígenas.

d) indígenas e branco-europeias.

5 - As plantas medicinais pertencem ao(a):

a) Grupo das Pteridófitas

b) Grupo das Gimnospermas

c) Grupo das Angiospermas

d) Todos os grupos vegetais apresentam representantes medicinais

6 - Quanto mais derivada na escala evolutiva é uma planta, maior a probabilidade de apresentar maior número de princípios ativos, pois:

a) apresenta maior capacidade de adaptação bioquímica ambiental

b) apresenta menor capacidade de adaptação bioquímica ambiental

c) apresenta maior complexidade bioquímica

d) apresenta menor complexidade bioquímica

7 - Cite duas plantas medicinais e para o que servem.

$\mathrm{R}:$ 
Quadro 2 - Questionário avaliativo-estrutural submetido aos alunos do terceiro ano do ensino médio da Escola Estadual Pirassununga, uma semana após a implantação do canteiro medicinal e da realização das aulas teórico-práticas pelos professores das disciplinas de Biologia e Química.

\section{QUESTIONÁRIO AVALIATIVO-ESTRUTURAL}

1 - Analise a afirmativa: a logística para a realização do projeto: indicação das plantas, formação dos grupos, obtenção das mudas por parte dos alunos, cultivo, compra de materiais por parte da escola e plantio das mudas de plantas medicinais, ocorreu a contento em relação ao tempo de execução das atividades ao longo do ano letivo. Quanto a essa afirmação você:a) Discorda totalmente

b) Concorda parcialmente

c) Concorda totalmente

2 - Analise a afirmativa: a organização dos próprios alunos em relação à obtenção das mudas e o plantio do canteiro de plantas medicinais foi peça chave para o sucesso obtido no desenvolvimento do projeto. Quanto a essa afirmação você:
a) Discorda totalmente
b) Concorda parcialmente
c) Concorda totalmente

3 - Analise a afirmativa: a mediação dos professores durante os trabalhos realizados em sala, durante o plantio das mudas e explicações finais sobre a necessidade, uso e conceitos biológicos e químicos de plantas medicinais foi importante para o aumento de conhecimento teórico prático dos alunos. Quanto a essa afirmação você:

a) Discorda totalmente

b) Concorda parcialmente

c) Concorda totalmente

4 - Analise a afirmativa: o conhecimento sobre plantas medicinais permite o resgate das tradições de antepassados relacionadas aos usos de fitoterápicos. Quanto a essa afirmação você:

a) Discorda totalmente

b) Concorda parcialmente

c) Concorda totalmente

5 - Analise a afirmativa: durante o desenvolvimento do projeto, muitos alunos buscaram conhecimento acerca do reconhecimento, plantio e utilidade das plantas medicinais com componentes mais idosos de suas famílias. Quanto a essa afirmação você:

a) Discorda totalmente

b) Concorda parcialmente

c) Concorda totalmente

6 - Faça um mini-texto (cinco a dez linhas), explicando o porquê da importância do projeto desenvolvido. Indique em sua redação os prós e contras do trabalho desenvolvido.

$\mathrm{R}:$ 


\section{RESULTADO E DISCUSSÃO}

\subsection{Análise do conteúdo biológico e químico}

A análise dos gráficos relacionados ao conteúdo biológico e químico apresentado aos alunos participantes do projeto instaurado na Escola Estadual Pirassununga demonstraram sucesso da intervenção teórico-prática, inter e transdisciplinar realizada, fato este corroborado pelo índice de acerto acima de $90 \%$, por parte dos alunos, em todas as questões objetivas relacionadas ao conteúdo ministrado (Figura 2).

Figura 2 - Gráficos indicando acertos e erros, referente ao questionário submetido aos alunos do terceiro ano do ensino médio da Escola Estadual Pirassununga, uma semana após a implantação do canteiro medicinal e da realização das aulas teórico-práticas pelos professores das disciplinas de Biologia e Química.
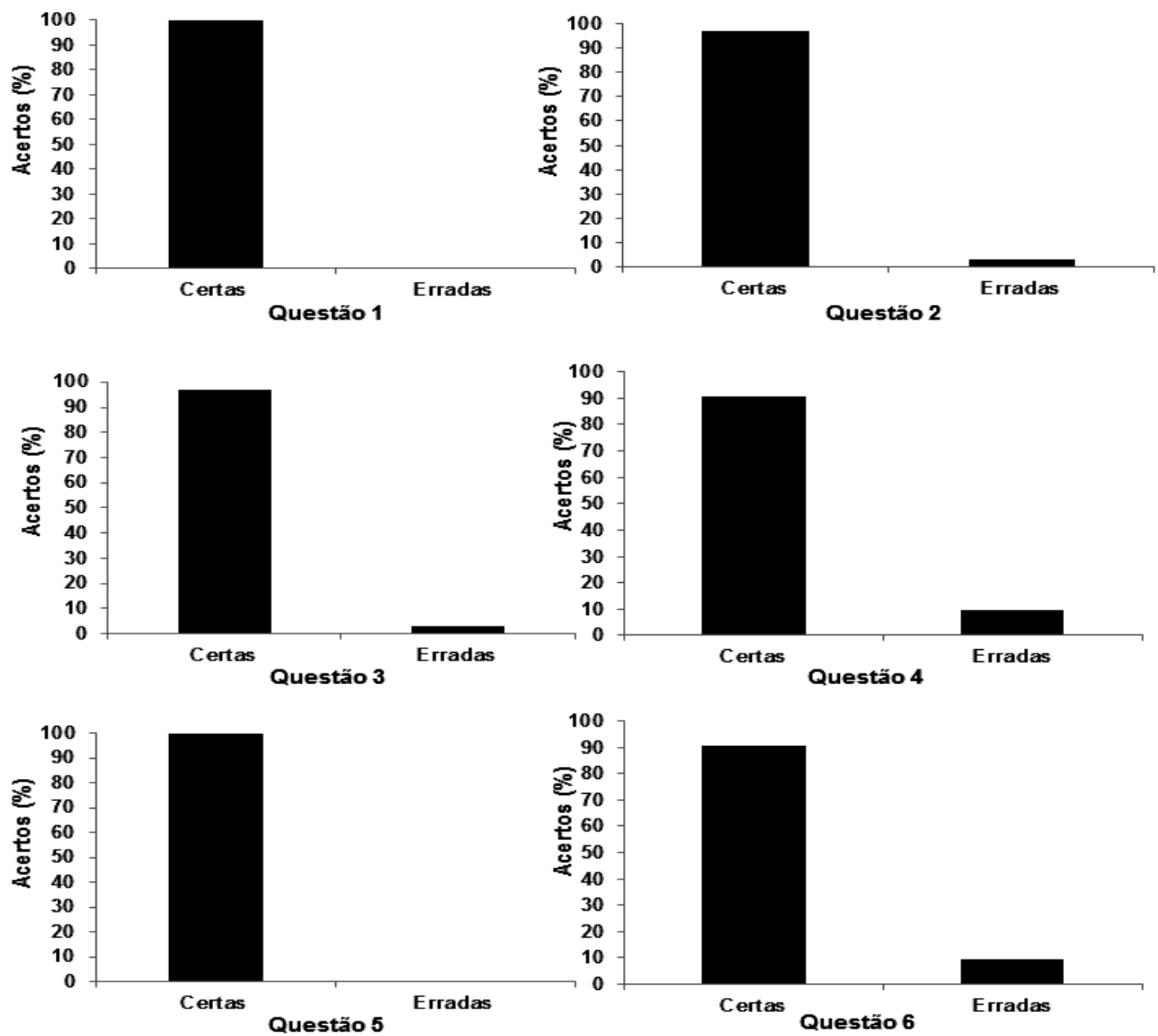

O contato dos discentes com os vegetais, em diferentes ambientes (natural ou urbano) permite que estes estejam mais atentos aos fatores abióticos que interferem no local de cultivo e nas relações bióticas existentes entre as plantas ( PINHEIRO DA SILVA; CAVASSAN, 2002; PINHEIRO DA SILVA, 2004; PEDROSO-DE-MORAES et al., 2015), levando-os a desenvolver consciência sobre a possibilidade de uso sustentável de grupos vegetais relacionadas à manutenção da saúde humana, como apontado nas questões de 1-4 (Quadro 1). 
Com relação à diversidade biológica e evolução, as análises, demonstraram entendimento sobre diversidade vegetal e capacidade bioquímica de adaptação ao ambiente, verificadas nas questões 5-6 (Quadro 1). Ressalta-se para as assertivas 5-6, que acertos nessas questões são importantes devido ao enfoque aos tópicos evolução e origem da biodiversidade por meio de especiação, dado pela Proposta Curricular do Estado de São Paulo (MENDONÇA et al., 2008) e pelo Exame Nacional do Ensino Médio (ENEM).

Com relação à questão dissertativa (questão 7), 100\% dos alunos responderam de forma correta o que foi solicitado, demonstrando a assimilação de conhecimento sobre a diversidade de plantas medicinais e sua possível utilização como fitoterápicos. Observou-se que as plantas mais citadas pelos alunos foram: Babosa, Bálsamo, Boldo-da-terra, Cavalinha, Erva-de-santa-maria e Melissa. As citações são interessantes visto que estas espécies estavam distribuídas entre as diferentes equipes, o que evidencia troca de informações entre os grupos e atenção dispensada pelos discentes nas aulas teórico-práticas ministradas pelos professores sobre os princípios ativos e possíveis usos de dessas plantas pelas populações carentes, como apontados pela OMS (OMS, 2000).

Outro fator a ser levado em consideração é a ação medicinal destas plantas, que se relacionam à cicatrização, cura de problemas hepáticos e renais e ação calmante, relatada corretamente pelos partícipes do projeto. Possivelmente, a escolha dessas plantas e a fixação do conteúdo relacionado a estas, está relacionado à frequência cotidiana com que os alunos estão expostos a informações e acometimentos desses estados e enfermidades.

Ressalta-se, também, o fato de aparecem nas respostas dessa questão, outras plantas medicinais que não foram listadas pelos professores, como: agrião, alfazema, hibisco e maconha, o que demonstra que o conteúdo ministrado gerou interesse capaz de fazer alguns alunos buscarem a conhecer mais sobre a diversidade de plantas e seu potencial medicinal, demonstrando autorregulação da aprendizagem.

As constatações evidenciam que projetos didáticos, com finalidade pedagógica, devem ser utilizados mais frequentemente por professores, deixando de lado nesse processo o ensino acadêmico teórico-clássico, ou seja, puramente expositivo (MORIN, 2002), uma vez que existe a necessidade premente do conhecimento ser construído na práxis cotidiana, pois, no sentido do Em Tese, a interdisciplinaridade é entendida como a necessidade de integrar, articular e trabalhar em conjunto (SEVERINO, 2001, p. 41). Sob este aspecto, professores de Ciências da Natureza podem ser um dos principais responsáveis pela implantação de aulas práticas inter e transdisciplinares nas unidades de ensino (UEs) (PEDROSO-DE-MORAES et al., 2015), uma vez que a reforma deve se originar dos próprios educadores e não do exterior (MORIN, 2002b, p.35).

Em nível investigativo comparativo, contudo, são escassos na literatura pedagógica artigos que abordem modelos metodológicos e aplicações teórico-práticas diretas relacionadas à interdisciplinaridade (PEDROSO-DE-MORAES et al., 2016) e ainda, mais raras as de cunho transdisciplinar, relacionadas ao ensino de Biologia (AUGUSTO et al., 2004) e de Química, constituindo as investigações da área, na maioria das vezes, apenas conceituações puramente teóricas, ou embasadas na realização de entrevistas com docentes e discentes (AUGUSTO; CALDEIRA, 2007) com relação à estas práxis dentro da área do conhecimento denominada Ciências da Natureza (PEDROSO-DE-MORAES et al., 2016).

\subsection{Análise da avaliação estrutural do projeto implantado}

Com relação à avaliação estrutural do projeto, a análise estatística realizada demonstrou que a realização da intervenção em diferentes períodos durante os quatro bimestres, ou seja, em etapas bem planejadas, contando com a ativa participação da equipe gestora na disponibilização de estrutura e 
materiais para seu desenvolvimento, do protagonismo direto dos alunos na obtenção das mudas e, subsequente plantio das plantas medicinais ocorrida com a supervisão dos docentes, foram condições sine qua non, para o sucesso da intervenção, como apontaram os resultados da avalição entre os discentes partícipes do projeto (Figura 3, Questões 1-3). Estas constatações corroboram a afirmativa de que:

Claramente, a elaboração de projetos educativos de escola envolve - dentre outros aspectos, mas de maneira central - a capacidade de eleger metas e objetivos e de organizar ações para atingi-los, acompanhando sua consecução e reorganizando-as, na medida do necessário. Isto é, envolve centralmente, a capacidade de planejar. No caso do planejamento educacional, esse ainda exige a capacidade de definir, selecionar e organizar "conteúdos" que deverão ser tematizados por meio de ações didáticas distribuídas no tempo e no espaço escolar (KLEIMAN, 2001, p.313).

Figura 3 - Gráficos indicando a avaliação estrutural do projeto referente ao questionário submetido aos alunos do terceiro ano do ensino médio da Escola Estadual Pirassununga, uma semana após a intervenção pedagógica (término do projeto).
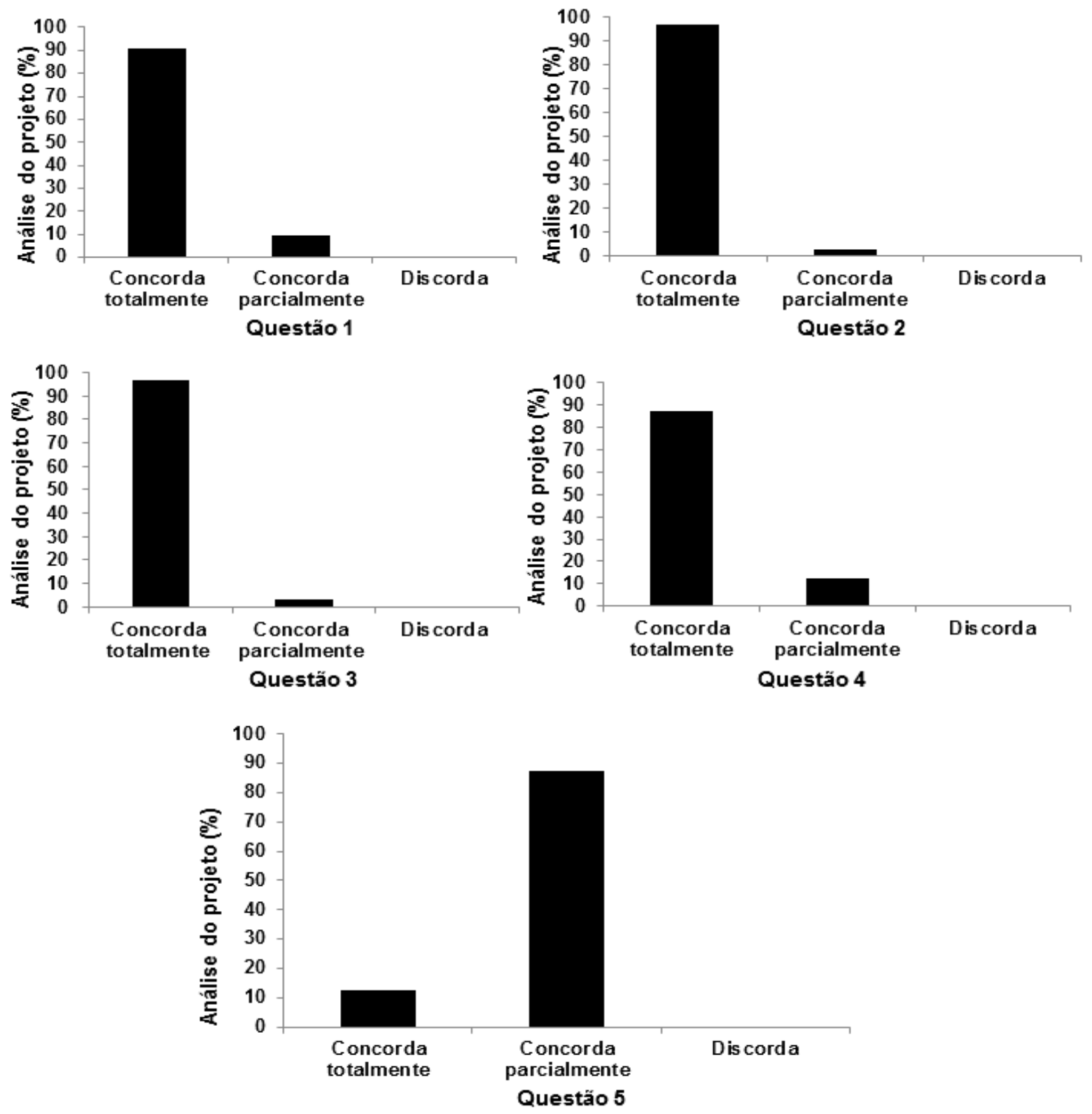
Ainda, nesta mesma linha de raciocínio, ressalta-se, em relação à elaboração de projetos didáticos, a importância do:

Repensar sobre a sistemática de planejamento, definindo metas a serem atingidas, em cronogramas exequíveis, fazendo com que as propostas tenham continuidade, prevendo recursos necessários, utilizando de forma plena, funcional e sem desperdício, os recursos disponíveis, definindo um acompanhamento e uma avaliação sistemática e não realizar o planejamento como tarefa burocrática, legalmente imposta, alienada, sem criatividade, desprovida de significado para os que dela participam..." (BRASIL [SEF/MEC], 1998, p. 85-88).

Verifica-se, portanto, na avaliação realizada pelos alunos e nos excertos supracitados que todos os pressupostos a cerca de uma eficiente e eficaz execução de projeto foram alcançados na intervenção realizada ao longo do ano, sendo esta constatação, também verificada na argumentação de alguns alunos na questão 6 (Quadro 2):

Mesmo com a dificuldade de achar e cuidar de algumas plantas, a união e o comprometimento da maioria dos colegas para a realização do projeto foi o que permitiu o sucesso da tarefa (Aluno 23).

A realização desse projeto foi possível devido ao trabalho dos professores, empenho dos alunos e a ajuda da escola (Aluno 27).

A escola nos ajudou com a compra de materiais para a execução do projeto e após o término, vai comprar também material para que a gente possa fazer uma cerca ao redor do canteiro medicinal. Isso vai ser muito bom, pois vai preservar as plantas dos animais noturnos (Aluno 30).

Com relação à análise das questões 5 e 6 do questionário estrutural avaliativo (Quadro 2, Figura 3), verifica-se que o ensino e/ou resgate de conteúdos Etnobotânicos em relação ao conhecimento e utilização de fitoterápicos foi considerado de grande importância pelos discentes. Isto se deve ao fato de que o uso de plantas medicinais, como medicamento para populações de baixa renda, tem importância mundial (SILVA; MARISCO, 2013), como amplamente discutido nas aulas teóricas ministradas durante a intervenção. Neste conteúdo foram abordados dados da Organização mundial da Saúde (OMS - ONU) que explicitam que $80 \%$ da população mundial utilizam práticas tradicionais na atenção primária, e desse montante, $85 \%$ utiliza plantas medicinais ou preparações destas (OLIVEIRA, 2010) para tratar e/ou curar os mais diversos quadros clínicos (OMS, 2000). Assim, apesar da utilização das plantas medicinais estarem diretamente associadas aos conhecimentos populares empíricos, gradativamente estão sendo reconhecidas e incorporadas ao saber científico, sendo este ramo do conhecimento um dos que mais tem contribuído para a difusão da utilização terapêutica das plantas medicinais (DANTAS; GUIMARÃES, 2007).

Sob esta perspectiva acima apresentada, plantas medicinais, apresentam-se como um importante conteúdo a ser trabalhado nas escolas públicas, não só pelo patrimônio natural e cultural, como também pela possibilidade de fornecer orientações a população juvenil/adolescente com relação a um maior aproveitamento dos recursos terapêuticos de origem natural, alertando a mesma sobre os problemas oriundos do uso indiscriminado de plantas medicinais e das plantas com efeitos tóxicos comprovados (OLIVEIRA; COUTINHO, 2006). Ainda, ações didáticas que estabeleçam vínculos entre o conhecimento Etnobotânico com o científico ministrado na escolar regular, estabelece um modo de redução da distância entre os conhecimentos populares e científicos, permitindo e enriquecendo o processo de ensinoaprendizagem, pois possibilita o protagonismo do aluno no processo de construção do conhecimento (COSTA, 2008). Estas colocações são explicitadas nas respostas dadas pelos discentes para a questão 6 (Quadro 2). 
O projeto foi importante para que os alunos do $3^{\circ}$. A, pudessem ter maior informação sobre a importância que as plantas têm em relação à saúde humana e os avanços medicinais que as mesmas trouxeram para a evolução médica. Além disso, trazer benefícios para pessoas de renda mais baixa que poderiam usar as plantas quando necessitarem (Aluno 3).

Este projeto foi importante, pois nos trouxe o conhecimento para que e, como cada planta é usada medicinalmente. Os benefícios que as plantas nos trazem, curando e ajudando a melhorar a saúde. O professor também nos ensinou sobre a OMS (ONU), falando que existe um tratamento fitoterápico para a população de baixa renda, dizendo para que esqueçamos o conhecimento relativo a essas plantas, pois é através dele que temos os remédios de hoje em dia, para tratar e curar doenças (Aluno 9).

O projeto foi importante, pois aprendemos muito sobre plantas que não conhecíamos e suas propriedades químicas que também podem ser fitoterápicas. As recomendações da OMS (ONU) deveriam ser mais informadas, pois seria bom para as pessoas de baixa renda (Aluno 13).

Notou-se com esses pequenos textos, que além dos alunos considerarem eficientes e eficazes os métodos e a estrutura implantada no processo, o planejamento procedimental também propiciou maior absorção de temas interdisciplinares e, principalmente, transdisciplinares, como as recomendações da OMS refletidas nas respostas para a primeira pergunta do conteúdo biológico e químico (Quadro 1, Figura 2 - questão 1). O mesmo aconteceu com a questão 2 desta seção da avaliação, como podemos observar no texto gerado para a questão 6 (Quadro 2):

O projeto foi importante para o conhecimento das plantas e para o que servem, aprendendo que dependente da dosagem, o uso da planta pode se tornar um veneno (Aluno 31).

Este fato também foi constatado para as questões 5 e 6 do Quadro 1/Figura 2, também mencionadas por um dos alunos no mini-texto do questionário avaliativo estrutural (Quadro 2- questão 6):

É de extrema importância esse trabalho, principalmente para o desenvolvimento de conhecimentos em relação à botânica (sistemática, morfoanatomia, fisiologia, evolução bioquímica e produção vegetal). Apesar do trabalho para encontrar as plantas com nomes bastante exóticos, foi muito bom e de experiência única poder conhecer um pouco da Botânica com cunho medicinal (Aluno 23).

Com relação à Etnobotânica em si (Quadro 2, Figura 3 - questões 4 e 5), foi observada à importância dada pelos discentes com relação, primariamente, ao conhecimento "perdido" ao longo das gerações sobre o uso de fitoterápicos e, secundariamente, o ensinar dos "mais velhos", principalmente por componentes familiares (avôs e avós) sobre o uso de plantas medicinais, como atestam os textos produzidos pelos discentes (Quadro 2 - questão 6), que se seguem abaixo:

O projeto foi importante, pois nos ensinou o valor das plantas medicinais, valor este, que foi perdido ao longo do tempo conforme as pessoas passaram a conviver menos com a natureza. É triste que algumas pessoas não tenham a oportunidade de aprender sobre isso (Aluno 4).

O trabalho desenvolvido foi importante, pois resgatou o passado, sendo que os nossos avós, que sabem mais sobre isso, nos ajudaram. Foi um momento de conhecimento sobre coisas que nem conhecíamos, sobre como resgatar essa cultura perdida (Aluna 6). 
Com o projeto, nós alunos conhecemos a utilidade das plantas medicinais. Nessa nova geração, as pessoas desconhecem que essas plantas são de fácil acesso, e que, por isso, tornam mais econômicos os cuidados com a saúde. Conhecimentos como esses são transmitidos pelos nossos antepassados e se perderam com o passar do tempo. O projeto resgatou isso (Aluno 8).

A importância está em resgatar as tradições dos antepassados relacionadas aos usos de fitoterápicos; informar a geração futura sobre essas plantas e os seus benefícios (Aluno 22).

A importância do projeto desenvolvido é o conhecimento trazido para os alunos. Trouxe interesse por parte de cada um e aprendemos também que ao invés de comprarmos remédios para curar doenças, podemos plantas ervas medicinais em nossas casas e com o auxílio de alguém experiente, como nossos avós, podemos consumi-las para sermos curados (Aluno 25).

O projeto realizado na escola resgatou o que nossa geração perdeu. Esse projeto é importante para que possamos sempre usar essas plantas para nossas vidas (Aluno 32).

O projeto ajudou a estudar as plantas e saber como usá-las, sem falar no convívio social. Isso sem falar na ajuda que os avós puderam dar por conhecerem e usarem mais ativamente tais plantas. $\mathrm{O}$ aprendizado também pode ajudar indiretamente na preservação da natureza (Aluno 35).

As repostas dos alunos para a questão 6 (Quadro 2) e a avaliação dos gráficos relativos às questões 4 e 5 (Figura 3), corroboram o fato de que o conhecimento sobre plantas medicinais é obtido geralmente de forma diversificada, sendo na maior parte das vezes, este conhecimento proveniente, principalmente dos familiares, secundariamente da mídia e por contato com enfermeiros, médicos, farmacêuticos e biólogos e, em menor escala por meio do que é ensinado na escola (SOUZA et al., 2015), evidenciando, portanto, que as Unidades de Ensino públicas podem utilizar amplamente este tema para a diversificação do ensino e promoção da aprendizagem dos conteúdos de Botânica e Química aos discentes. Além disso, o escrutínio dos depoimentos permite a inferência também, de que indiretamente o projeto permitiu integração e troca de informações dentro do ambiente familiar, entre as diferentes gerações, o que também foi constatado em trabalho relacionado à excursão pedagógica realizada pela mesma UE, para o ensino do conteúdo interdisciplinar Biogeografia no Parque Estadual de Porto Ferreira - SP, que abordou suscintamente a importância do Cerrado para a indústria farmacêutica (PEDROSO-DE-MORAES et al., 2015).

\section{CONCLUSÃO}

A intervenção realizada com os alunos do $3^{\circ}$. Ano A do Ensino Médio da Escola Estadual Pirassununga, permitiu a integralização dos conteúdos de Botânica (Sistemática, Morfoanatomia, Fisiologia, Evolução Bioquímica e Produção Vegetal), com os de Química (Reconhecimento de moléculas e funções orgânicas), por meio de aulas teóricas e práticas sobre obtenção, cultivo, plantio, princípios ativos e utilização de plantas medicinais (fitoterápicos). A interdisciplinaridade, a transdisciplinaridade, e o desenvolvimento de aulas práticas e teóricas diversificadas, foram às formas com as quais se atingiu a eficácia em relação ao ensino-aprendizagem, atestadas pelos resultados obtidos nas avaliações estatísticas e nos depoimentos dos discentes com relação à importância dos conhecimentos Etnobotânicos e das recomendações da OMS sobre a utilização de plantas medicinais por pessoas de baixa renda. Relaciona-se 
também o sucesso da intervenção com o planejamento sistemático do projeto que possibilitou a integração da equipe gestora, docentes e alunos na realização das etapas bimestrais que culminaram na autorregulação da aprendizagem do alunado.

\section{REFERÊNCIAS}

ALBUQUERQUE, U. P. de. Introdução à etnobotânica. 2 ed. Rio de Janeiro: Interciência, 2005, 93p.

AUGUSTO, T. G. S. et al. Interdisciplinarity: conceptions of the teachers for the Natural Sciences Area in formation in service. Ciência \& Educação, v. 10, p. 277-289, 2004

AUGUSTO, T.G.S.; CALDEIRA, A. M. A. Dificuldades para a implantação de práticas interdisciplinares em Escolas Estaduais, apontadas por professores da área de Ciências da Natureza. Investigações em Ensino de Ciências, v.12, p. 139-154, 2007.

AMOROSO, M. C. M. Uso e diversidade de plantas medicinais em Santo Antônio de Levenger, MT, Brasil. Acta Botânica Brasílica, v.16, n.2, p. 189-203. 2002.

BIZZO, N. Ciências: fácil ou difícil. São Paulo: Ed. Ática, 1998.144p.

BRASIL (SEF/MEC). Parâmetros Curriculares Nacionais $-3^{\circ}$ e $4^{\mathbf{0}}$ Ciclos do Ensino Fundamental. Língua Portuguesa/Introdução. Brasília, DF: SEF/MEC. 1998. Pp. 85-88.

COSTA, R. G. A. Os saberes populares da etnociência no ensino das ciências naturais: uma proposta didática para aprendizagem significativa. Revista Didática Sistêmica, v. 8, n.1, p. 22-31. 2008.

COSTA, J. C.; MARINHO, M. G. V. Utilização de plantas medicinais como recurso didático para o ensino de ciências e Biologia. In: ENCONTRO DE INICIAÇÃO A DOCÊNCIA DA UFCG: LINGUAGENS, DIVERSIDADE E DOCÊNCIA NO PIBID - UFCG, 4. Anais... 2012, Pp. 1-6.

DANTAS, I. C.; GUIMARÃES, F. R. Plantas medicinais comercializadas no município de Campina Grande, PB. Revista de Biologia e Farmácia, v. 1, n. 1, p. 1-13, 2007.

KLEIMAN, A. B. (Org). A Formação do Professor: Perspectivas da Lingüística Aplicada. Campinas: Mercado de Letras, 2001. Pp. 313-335.

KRASILCHIK, M. Prática de Ensino de Biologia. 4.ed.São Paulo: Editora da Universidade de São Paulo, 2004.

MORIN, E. A cabeça bem-feita: repensar a reforma, reformar o pensamento. 7. ed. Rio de Janeiro: Bertrand Brasil, 2002. 131p.

MORIN, E. Educação e complexidade: os sete saberes e outros ensaios. São Paulo: Cortez, 2002b. 114p.

OLIVEIRA, P. S. Plantas medicinais numa comunidade rural assentada no município de Cordeirópolis-SP: Etnofarmacologia e Educação. 2010. 93f. Dissertação (Mestrado em Educação). Instituto de Biologia da Universidade Estadual de Campinas, UNICAMP. Campinas, São Paulo.

OLIVEIRA, P. S.; COUTINHO, K. R. Conhecimento popular sobre plantas medicinais: tema gerador na educação de jovens e adultos. ETIC - Encontro de Iniciação Científica, v. 2, n. 2, p. 41-54. 2006. 
OMS - ORGANIZACIÓN MUNDIAL DE LA SALUD. Situación regulamentaria de los

medicamentos: uma reseña mundial. Taducción del inglés: Organización Panamericana de la Salud.

Washington: OPAS, 2000. Pp. 62.

PEDROSO-DE-MORAES, C.et al. PRÁTICA DE CAMPO: APRENDIZAGEM SOBRE

BIODIVERSIDADE E PRESERVAÇÃO AMBIENTAL VERIFICADA EM DISCENTES DA ESCOLA

ESTADUAL PIRASSUNUNGA, SP.. Nucleus, Ituverava, v. 12, n. 1, p. 361-370, apr. 2015. ISSN 1982-

2278. Disponível em:

<http://www.nucleus.feituverava.com.br/index.php/nucleus/article/view/1415/1784>. Acesso em: 15 may 2017. doi:http://dx.doi.org/10.3738/1982.2278.1415.

PEDROSO-DE-MORAES, C.et al. ANÁLISE DE INTERVENÇÃO INTERDISCIPLINAR NO $1^{\circ}$. ANO DO ENSINO MÉDIO DA ESCOLA ESTADUAL PIRASSUNUNGA, SP.. Nucleus, Ituverava, v. 13, n. 2, p. 17-32, nov. 2016. ISSN 1982-2278. Disponível em:

〈http://www.nucleus.feituverava.com.br/index.php/nucleus/article/view/1595/2115〉. Acesso em: 15 may 2017. doi:http://dx.doi.org/10.3738/1982.2278.1595.

PEREIRA, S. M.; SIQUEIRA, A. B. Abordagem etnobotânica no ensino de Biologia. In: SIMFOP. SIMPÓSIO SOBRE FORMAÇÃO DE PROFESSORES - EDUCAÇÃO BÁSICA, 5: DESAFIOS FRENTE A DESIGUALDADES EDUCACIONAIS, 8., 2013, Campus Universitário de Tubarão. Anais... Tubarão-SP: SIMFOP, 2013.

PINHEIRO DA SILVA, P. G.; CAVASSAN, O. A representatividade das ilustrações botânicas presentes nos livros didáticos de ciências no processo de ensino e aprendizagem. In: ENCONTRO PERSPECTIVAS DO ENSINO DE BIOLOGIA, 8., 2002, São Paulo. Anais...São Paulo: FEUSP, 2002. 1 CD-ROM.

PINHEIRO DA SILVA, P. G. As ilustrações botânicas presentes nos livros didáticos de ciências: da representação impressa à realidade. 2004. 189 p. Dissertação (Mestrado em Educação para a Ciência) Faculdade de Ciências da Universidade Estadual Paulista "Júlio de Mesquita Filho", Bauru.

SENICIATO, T.; CASSAVAN, O. Aulas de campo em ambientes naturais e aprendizagem em ciências um estudo com alunos do fundamental. Ciência \& Educação, v. 10, p. 133-147, 2004.

SEVERINO, A. J. O conhecimento pedagógico e a interdisciplinaridade: o saber como intencionalização da prática. In: FAZENDA, I. C. A. (Org.). Didática e interdisciplinaridade. Campinas: Papirus, 2001. p. 41.

SILVA, L. F.; CARVALHO, L. M. A Temática ambiental e o ensino de Física na escola média: algumas possibilidades de desenvolver o tema produção de energia elétrica em larga escala em uma situação de ensino. Revista Brasileira de Ensino Física, v. 24, p. 342-352, 2002.

SILVA, L. L. da; DINIZ, E. M.; PEDROSO-DE-MORAES, C. Análise da percepção ambiental de um grupo de alunos com necessidades educacionais especiais educacionais. Revista Científica da

FHO|UNIARARAS, v. 2, p. 1-9, 2014.

SOUZA, V. A.; LIMA, D. C. S.; VALE, C. M. Avaliação do conhecimento Etnobotânico de plantas medicinais pelos alunos do Ensino Médio da cidade de Inhumas, Goiás. Revista Eletrônica de Educação da Cidade da Faculdade Araguaia, v. 8, n. 1, p. 13-30, 2015.

THIOLLENT, M. Metodologia da pesquisa-ação. 10. ed. São Paulo: Autores Associados, 2000. 235p.

TOP TROPICAL. Tropical plant catalog: Cissus sicyoides. Disponível em: <

http://toptropicals.com/catalog/uid/Cissus sicyoides.htm> Acesso: 08 nov. 2016. 